\title{
El concepto de cuerpo en la poesía de José Watanabe. Hermenéutica de la relación médico-enfermo
}

\author{
Concept of body in Jose Watanabe's poetry. Hermeneutics of
} doctor-patient relationship

\author{
José Luis Li Ning Anticona ${ }^{1}$ \\ 1 Profesor de Psiquiatria, Facultad de Medicina, Universidad Nacional Mayor de San Marcos.
}

\begin{abstract}
Resumen
El estudio correlaciona tres poemas de José Watanabe (1946-2007) -"El ojo", "Mi casa" y "Como el peje-sapo"- con la noción existencialista de cuerpo. Se delimita tres cuerpos: el biológico, el consciente y el cultural, que facilitan la descripción fenomenológica de la relación médico- enfermo.

Palabras clave: Cuerpo humano, poesía, existencialísmo, relaciones médico-paciente.

Abstract

The following study correlates three poems of Jose Watanabe (1946-2007) -"El Ojo", "Mi Casa", and "Como el Peje-sapo"- with the existentialist notion of the body. Three bodies are delimited, a biologic, conscious, and a cultural one, in order to facilitate the phenomenological description of doctor-patient relationship.
\end{abstract}

Key words: Human body, poetry, existencialism, physician-patient relations.

\section{An Fac med. 2012;73(4):335-43}

\section{INTRODUCCIÓN}

Proponemos un estudio de caso: el testimonio del poeta trujillano José Watanabe Varas (1946-2007), quien publicó, en 1999, Cosas del cuerpo (2), después de haber sido operado dos veces de cáncer pulmonar. Sin duda, este padecimiento lo llevó a meditar sobre su corporeidad enferma y poetizar sobre ella. La conceptualización de 'cuerpo' que se desprende de algunos de sus poemas nos ha llevado a consultar las corrientes filosóficas que han tratado el mismo tema, sobre todo la existencialista, en un cotejo de hermenéutica poéticofilosófica cuyo impulso inicial fue inspirado en Filosofía y poesía: dos aproximaciones a la verdad, de Gianni Vattimo y Maurizio Ferraris ${ }^{(1)}$, para quienes: ...el nexo entre poesía y filosofía se rastrea no en la indigencia histórica del pensamiento, [...] sino en el misterio, que mancomuna este múltiple poiein, para el cual pensar y poetizar exigen un construir, que es al mismo tiempo retomar el viejo sendero e instituir a priori (pero siempre a partir de las huellas predeterminantes) un tejido de versos o de argumentos (p.12).

En nuestra condición de profesionales empíricos, el concepto de cuerpo es obvio. Sin embargo, creemos que la vivencia emocional de tener el cuerpo enfermo expresada poéticamente y la especulación filosófica pueden enriquecer la visión del encuentro entre el médico y el enfermo, descrita, habitualmente, desde el punto de vista del primero.
Un axioma de la comunicación pragmática, basado en los principios de la teoría de los sistemas y de la cibernética, nos advierte que filosofía y poesía se encuadran en dos tipos de comunicación con capacidad sintáctica y semántica diferentes: la comunicación digital y la analógica ${ }^{(3)}$. El lenguaje filosófico, estrictamente lógico, que busca la precisión racional unívoca, puede ser catalogado como 'digital' y el lenguaje poético como 'analógico'. El segundo recurre a construcciones lingüísticas que a partir de la ambigüedad transmiten inefables emociones estéticas que dan curso a interpretaciones múltiples y diversas. Por eso, acudimos al correlato de los textos para ajustar la interpretación. 


\section{EL CONCEPTO FILOSÓFICO 'CUERPO'}

José Ferrater Mora ${ }^{(4)}$ inicia su definición del concepto 'cuerpo' delimitando tres acepciones: la primera se refiere a todo objeto físico con propiedades sensibles; la segunda es la materia orgánica del hombre y los animales; y, la tercera, la materia del cuerpo humano:

Desde los griegos se ha considerado la noción de cuerpo en los tres sentidos antes mencionados [...], pero el interés por 'el cuerpo' en cuanto 'mi cuerpo' se ha abierto paso especialmente en la época contemporánea. Cuando, en el pasado, se ha centrado el interés en la acepción (3), la noción de cuerpo ha sido considerada en relación con el alma, planteándose el problema cuerpo-alma, o cuerpo-espíritu, cuerpo-psique, cuerpo-mente, y otros (p. 690).

En nuestra revisión evitamos abordar la dicotomía cuerpo-alma; la centramos en el concepto 'cuerpo', con la finalidad de pulsar dos conceptos de interés médico: 'enfermedad' y 'relación médico-enfermo'.

Según Aristóteles, el cuerpo es substancia, tiene extensión, su propio espacio. Algunos platónicos y pitagóricos consideran al cuerpo humano como sepulcro del alma, mientras que para los estoicos y epicúreos la realidad es material o 'corporal'. Los escolásticos de la edad media se preocuparon por la unión entre materia y forma. En la época moderna continuaron las disquisiciones sobre la relación entre cuerpo y alma con algunas pequeñas variantes referidas al 'cuerpo material', que informa de la influencia de la Física.

En el siglo XVII, el racionalismo formulado por René Descartes considera la existencia de tres sustancias: el pensamiento, la extensión y Dios. Establece un dualismo sustancial entre alma -res cogitans, el pensamiento- y el cuerpo -res extensa, la extensión. Los otros dos grandes representantes del racionalismo fueron Spinoza y Leibniz. Baruch de Spinoza, crítico del cartesia- nismo, reduce las tres sustancias a una sola, la sustancia divina infinita; la sustancia es la realidad. Elaboró una doctrina general de los cuerpos: 'un individuo' se compone de cuerpos; las partes de un individuo se ponen en contacto unas con otras. Por su parte, Gottfried Leibniz contribuyó a la metafísica con la teoría de las mónadas, elementos últimos del universo que en el ámbito metafísico corresponden a los átomos del ámbito físico; son centros de fuerza, mientras que el espacio, la materia y el movimiento son meramente fenomenales. Cada ser humano es una mónada, igualmente Dios. Las mónadas se han deshecho de la problemática interacción entre la mente y el cuerpo ${ }^{(4)}$. Para Thomas Hobbes toda realidad es corporal, siendo la filosofía el estudio de los cuerpos y de sus movimientos. Define al cuerpo como "lo que no depende de nuestro pensamiento y coincide con, o es coextensivo a, una parte del espacio" ${ }^{(4)}$.

Durante los siglos XVIII y XIX aparecen los conceptos 'cuerpo', 'espíritu', 'materialismo' y 'espiritualismo', en dos grupos de autores. Lo más común ha sido tratar de 'reducir' un tipo de realidad a la otra: puro dualismo, ocasionalismo, armonía preestablecida y el 'paralelismo psicofísico' (4).

La noción de 'cuerpo humano' ha sido objeto de numerosas investigaciones y especulaciones en el siglo XX. Así, Henri Bergson ha dicho que una de las imágenes que se le presentan cuando funcionan sus sentidos es una que secciona a todas las demás en tanto que "no solo la conozco desde fuera, por las percepciones, sino también desde dentro, por las afecciones: es mi cuerpo" (Oeuvres, ed. Robinet, 1959, pág. 169) (4). Edmund Husserl ha indicado que el cuerpo desempeña fenomenológicamente un papel fundamental. Cuerpo y alma forman el 'mundo circundante' del espíritu (que es la verdadera concreta individualidad y personalidad). Aunque cuerpo y alma son determinantes para el espíritu, este puede mover el cuerpo 'en su libertad'.
El cuerpo es una realidad bilateral cuando la consideramos como cuerpo, es decir, cuando prescindimos de que es una cosa y, con ello, algo determinable como naturaleza física. De este modo se constituye: 1) el cuerpo estesiológico, que en tanto que sintiente depende del cuerpo material, pero no es identificable con él; 2) el cuerpo volitivo, que se mueve libremente y es algo idéntico con respecto a los distintos movimientos posibles, que el espíritu realiza en él libremente ${ }^{(4)}$.

Gabriel Marcel, representante de la corriente del existencialismo cristiano, paralelo al existencialismo 'ateo' de Sartre, dice:

"El mundo existe para mí [...] en el sentido riguroso del término 'existir', en la medida en que mantengo con él relaciones del tipo de las que mantengo con mi cuerpo; es decir, en tanto que estoy encarnado" (Journal Métaphysique, 3ae ed., 1927, pág. 261) [...] la relación entre mi cuerpo y yo es $[\ldots]$ de naturaleza absolutamente singular. De hecho, la relación entre el alma y el cuerpo (o, más exactamente, la relación entre yo y $\mathrm{mi}$ cuerpo) no es un problema, sino un misterio. El cuerpo puede ser, ciertamente, 'objetivado', convertido en objeto de conocimiento científico. Pero entonces no es ya propiamente 'mi cuerpo' (no es el cuerpo de 'nadie'). Es una simple muestra ${ }^{(4)}$.

Por otro lado, Jean-Paul Sartre, según resume Ferrater Mora,

ha elaborado una minuciosa fenomenología del cuerpo en tanto que "lo que mi cuerpo es para mî", a diferencia de la 'objetividad' y 'alterabilidad' en principio de cualquier cuerpo como tal. Mejor dicho, el cuerpo aparece bajo tres dimensiones ontológicas. En la primera, se trata de un 'cuerpo para mî', de una forma de ser que permite enunciar 'yo existo mi cuerpo'. Dentro de esta dimensión, el cuerpo es siempre 'lo trascendido'. Pues, el cuerpo que 'yo existo' es lo que "yo trasciendo 
continuamente hacia nuevas combinaciones de complexos" (L'Être et le Néant, 5aㅡ ed., 1945, pág. 390), y por eso mi cuerpo pertenece "a las estructuras de la conciencia no-tética (de) sí mismo" (op.cit., pág. 394). En la segunda dimensión, el cuerpo es para otro (o bien el otro es para mi cuerpo); se trata entonces de una corporeidad radicalmente diferente de la de mi cuerpo para mí. En este caso se puede decir que "mi cuerpo es utilizado y conocido por otro". "Pero, en tanto que yo soy para otro, el otro se revela a mí como el sujeto para el cual soy objeto. Entonces, yo existo para mí como conocido por el otro, en particular en su facticidad misma. Yo existo para mí como conocido por otro en forma de cuerpo" (op. cit., págs. 418-19). Tal es la tercera dimensión ontológica del cuerpo dentro de la fenomenología ontológica del ser para otro y de la existencia de esta alteridad ${ }^{(4)}$.

También Maurice Merleau-Ponty ha analizado in extenso el problema del cuerpo y su percepción:

una serie de imágenes fenomenológicas que dejan subsistente, por así decirlo, la 'consistencia' del cuerpo. Pues el cuerpo -el propio cuerpo-no es un objeto. El cuerpo como objeto es, a lo sumo, el resultado de la inserción del organismo en el mundo del 'en sî' (en el sentido de J. P. Sartre) $[\ldots]$

Parece que la fenomenología del cuerpo en el sentido de MerleauPonty da como resultado el cielo abierto por Descartes con la separación entre cuerpo y alma y solucionar todos los debates habidos durante la época moderna acerca de esta cuestión [...] Así, la "unidad del alma y del cuerpo no queda sellada por medio de un decreto arbitrario entre dos términos exteriores, uno objeto y el otro sujeto. Se realiza a cada instante en el movimiento de la existencia. Con ello, Merleau-Ponty confirma la imposibilidad de establecer una dualidad entre 'mi cuerpo' y 'mi subjetividad', cualidad que, según lo ha hecho observar Alphonse de Waelhens, desaparece tan pronto como se concibe la existencia como un 'ser-en-el-mundo' (4).

Finalmente, Gilbert Ryle considera que la separación cartesiana entre pensamiento y extensión sería un error de lenguaje, un error categorial:

La absorción implica la admisión de que ambos pertenecen al mismo tipo lógico. Las dos expresiones tradicionales $[\ldots]$ indican $[\ldots]$ dos sentidos distintos de 'existe'. Con esto anula toda distinción entre lo 'público' y lo 'privado' en las actividades psíquicas, lo cual equivale a aproximar cuerpo y subjetividad en un sentido parecido al establecido por MerleauPonty ${ }^{(4)}$.

\section{EL CUERPO EN TRES POEMAS DE WATANABE}

En 1986, Watanabe fue operado de un cáncer pulmonar en Alemania. En su convalecencia, en el Perú, pasó un largo período de suspenso ante la siempre posible recidiva ${ }^{(5)}$. En 1989 publicó el segundo de sus poemarios: El huso de la palabra ${ }^{(6)}$. De allí hemos tomado el

\section{EL OJO}

1 La primera operación de tu insomnio es un juego de los tiempos: te revisas y confirmas que ni tus manos ni tus pies

5 se han desprendido como colas de lagartija. Todo tu cuerpo sigue amarrado dentro de tu piel.

La otra operación de tu insomnio no te es accesible. Es el ojo interior

10 que navega dentro de tu carne. Es del ojo que te recorre

y observa cada uno de tus órganos y se guarda el secreto.

El ojo ha nacido contigo

15 para fisgar tu lento desastre, ninguna otra cosa sabe de ti, ignora si vives en esta ciudad o en otra, no conoce el papel donde escribes sobre su perversidad y tal vez no conoce la perversidad. Él sólo sabe

20 de tu adentro.

Pronto se acabará esta noche con su estrella compasiva en la ventana

y tampoco hoy sabrás

si el ojo que viaja por tus confines

25 es el ojo de Dios que observa maravillado a cada órgano

haciendo incansablemente y todavía lo suyo o si es el indiferente pero acucioso ojo de la nada. 
tercer poema que analizamos: "Como el peje-sapo". En 1994 requirió otra intervención quirúrgica, en Lima, por otro cáncer pulmonar, cinco años después del primero. Cosas del cuerpo fue publicado en 1999. A este libro pertenecen los dos primeros poemas que hemos seleccionado: "El ojo" y "Mi casa".

\section{1. "EL OJO"}

Los poemas presentan una característica formal propia del estilo poético de Watanabe, dos partes bien definidas en cuanto al referente real: la primera es la descripción de un hecho observado en la vida cotidiana, es 'realista', ubica a la acción general y sirve de apoyo para desarrollar la otra, 'ideal' de naturaleza puramente imaginaria o de elucubración. El efecto poético final se alimenta de la superposición de estos dos planos.

El título del poema ("El ojo") anuncia un mundo perceptivo: en sus noches de insomnio (léase "de ojos abiertos"), el yo poético pasa revista a su cuerpo; verifica si todas sus partes están donde corresponde. El chequeo, de fácil realización con lo visible y palpable, fracasa en el interior del cuerpo, inaccesible. Esta frustración le sirve de estímulo para la fantasía; a partir de allí, todo es elucubración poética: imagina, entonces, la existencia de un ojo interno congénito, que se desplaza en sus entrañas como sonda exploradora para 'fisgar' su 'lento desastre', que no informa de sus hallazgos.

La función del ojo dentro del cuerpo, que el yo consciente anhela para sí mismo, es calificada como perversa por su actividad voyerista autónoma y hermética. Desinformado, solo posee la convicción de que allí está, de que 've' y 'conoce' un deterioro no perceptible para él. En este sentido, el ojo autónomo, desdoblado del ojo consciente, representa a una conciencia autónoma, desdoblada -a su vez- del yo consciente; es una metáfora de su conciencia proyectada como una doble conciencia. El enfrentamiento a ese mundo separa- do de él mismo, pero existente en sus propias entrañas, presentido como poderoso y destructivo (enfermo), lo incita a divagar sobre la esencia y el sentido del existir. Así, el autor delimita una actividad enigmática, propia del ojo interno, cuya naturaleza se resiste a la clasificación y, por eso, 'escolásticamente', la ubica en el límite de lo trascendente, en la encrucijada de la teología y la filosofía: ies Dios que continúa su tarea de hacedor o es la indiferente nada?

Los conceptos 'Dios' y 'la nada' despiertan imágenes metafóricas espaciales de inmensidad, con lo cual, el interior del cuerpo estalla en amplitud: el pequeño mundo de las vísceras contiene al infinito (El universo en una cáscara de nuez del físico Stephen Hawkins ${ }^{(7)}$ ). La tensión suscitada por la evocación de esta doble antinomia Dios/nada, inmensidad/pequeñez conduce al lec- tor al estallido poético final, a la única alternativa ontológica posible: el ojo del cuerpo (su esencia última) está allí, existe; el Dasein de Heidegger y del existencialismo.

La filiación existencialista que adjudicamos al poema va más allá del desenlace poético y de la metáfora óculocorporal, si consideramos la disquisición teórica sobre el cuerpo planteada por Merleau-Ponty en su obra monumental Fenomenología de la percepción ${ }^{(8)}$. El ojo interno de Watanabe 'existe' porque existe un cuerpo perceptible para él.

Desde el punto de vista de la psicología médica, el poema refleja la situación del paciente que tiene conciencia de estar enfermo; pero, (aparentemente asintomático) ignora cuánto y cómo. El sufrimiento de la ansiedad ante la incertidumbre es vivida como perversidad del ojo interno, que sabe y no dice.

\section{CASA}

1 Mi vecino

estira su casa como un tejido que le ajusta.

No debería burlarme,

si yo mismo vivo inmensamente pegado a mi casa, tanto

5 que a veces las paredes tienen marchas

de mi sangre o mi grasa.

Sí, mi casa es biológica. En el aire

hay un latido suave, un pulso que con los años se ha concertado con el mío.

10 Mi casa es membranosa y viva, pero no es asunto

uterino. Estoy hablando del lugar de mi cuerpo

que he construido, como el pájaro aquel,

con baba

15 carne.

Afuera soy, como todos, del trabajo y la economía, aquí

de mi cuerpo desnudo

$y$, a veces, de una mujer

que se aviene a ser, como yo, otro órgano dentro de este

20 pulposo

tercer

piso. 


\section{2. "MI CASA"}

"Mi casa" es un complemento del poema anterior; pertenecen a la misma sección de Cosas del cuerpo. "El ojo" es el mudo testigo del desastre del espacio corporal interno, mientras que "Mi casa", cuyo interior está habitado por la voz lírica, es la proyección externa del propio cuerpo, con quien comparte sustancia: "Estoy hablando del lugar de mi cuerpo / que he construido, como el pájaro aquel, / con baba / y donde espacio y función intercambian / carne". El yo poético monologa en el interior de su propio cuerpo exterior, como el ojo vigilante del poema previo; pero, esta vez, no solo conoce todo sino que, al hacerse acompañar "de una mujer / que se aviene a ser, como yo, otro órgano dentro de este / pulposo / tercer / piso", convierte a su casa, ya no en el lugar de la supuesta perversión egoísta del ojo autónomo, sino en el ámbito donde puede compartir la existencia y probablemente también sus goces, es el lugar del 'nosotros'. el locus amoenus de la literatura medieval, el lugar del placer; en oposición al locus horridus del sufrimiento (angustia).

Psicológicamente, la vivienda es la ampliación del yo corporal y, a la vez, la reducción del mundo, un lugar donde el enfermo pasa gran parte de su vida. En la soledad del insomnio, el yo poético se desdobla, toma distancia de su cuerpo y lo convierte en objeto de contemplación; mide el alcance de sus sentidos y, de acuerdo con ellos, lo amplía en dos dimensiones: una interna, invisible y silente, por consiguiente inalcanzable, y una externa, cuya interioridad está expuesta a su visión y tacto.

Se establece así, un cuerpo diseñado espacialmente como tripartito, cuya parte central está constituida por el yo que razona, siente y tiene voluntad; el cuerpo interno inaccesible; y el externo construido con sus manos. Es evidente la correspondencia de estos espacios, sus atributos y sus límites borrosos, con la naturaleza bio-psico-social concebida modernamente para el ser humano. También lo es con los tres mundos humanos del filósofo Karl Popper y el neurólogo John Eccles ${ }^{(9)}$ : el Mundo 1 es material, biológico; el Mundo 2 es psicológico, el de la experiencia consciente; y el Mundo 3 es cultural. Traducidos al léxico watanabeano, diremos: Cuerpo 1, Cuerpo 2 y Cuerpo 3.

Los espacios corporales metafóricos, reversibles y de límites difuminados, trazados por el poeta, nos permite ubicar algunas entidades nosográficas y terapéuticas que se resisten a la simplificación médica basada en la dicotomía mente-cuerpo, como el efecto placebo, la hipocondría y el miembro fantasma.

El tránsito poético del cuerpo por el cuerpo, que pasa de lo interno a lo externo, que a su vez es interno, a similitud de las series de cajas chinas o de matriuskas rusas, donde -sucesivamente- la una contiene a la otra, relativiza a los términos locativos 'dentro' y 'fuera' tratados por Gastón Bachelard ${ }^{(10)}$ en "La dialéctica de lo de dentro y de lo de fuera":

Ante todo hay que comprobar que los dos términos, fuera y dentro, plantean en antropología metafísica problemas que no son simétricos. Hacer concreto lo de dentro y vasto lo de fuera son, parece ser, las tareas iniciales, los primeros problemas, de una antropología de la imaginación. Entre lo concreto y lo vasto, la oposición no es franca. Al menor toque, aparece la disimetría. Y así sucede siempre: lo de dentro y lo de fuera no reciben de igual manera los calificativos, esos calificativos que son la medida de nuestra adhesión a las cosas. No se puede vivir de la misma manera los calificativos que corresponden a lo dentro y a lo de fuera (p.253).

Sartre es más contundente en El Sery la Nada ${ }^{(11)}$, cuando de inicio señala que el pensamiento moderno intenta suprimir cierto número de dualismos: "Las apariciones que manifiestan lo existente no son ni interiores ni exteriores: son equivalentes entre sí, y remiten todas a otras apariciones, sin que ninguna de ellas sea privilegiada" (p.11).

\section{3. "COMO EL PEJE-SAPO"}

El tercer poema, "Como el peje-sapo", versa sobre el cuerpo consciente y el interno o visceral antes de la intervención quirúrgica. Aquí, a pesar de la presencia de la enfermedad, aludida cautelosamente como 'el peligroso borde', dentro de una situación genérica más referida a la antesala de la operación quirúrgica, tampoco aparecen los conceptos 'vida' ni 'muerte' (con excepción de un contundente 'no morirás'). Más allá de las razones estilísticas que justificarían esta ausencia, el autor deja entrever que la enfermedad, la vida y la muerte solo se dan en el cuerpo, la única certeza de la conciencia. De ahí la universalidad en la búsqueda de su trascendencia: todas las culturas siempre se han preocupado por el cuerpo 'físico' y han elaborado complicadísimos procedimientos y rituales funerarios (momificación o incineración) para conservarlo, protegerlo, o recuperarlo íntegro al final de los tiempos. "Todo cuerpo es tótem" (v. 17) sentencia el poeta.

Es el poema de la ansiedad -o más bien del temor- en el momento preoperatorio, el 'peligroso borde'. También lo es de la manera como el poeta supera el miedo: poco antes de ser adormecido por la anestesia, el yo lírico toma distancia de su cuerpo y se despide de él como el padre de su hijo antes de la batalla, dándole -y dándose- valor al reconocer su pertenencia a la comunidad de todos los cuerpos. Se dice a sí mismo: "Callada tu mente y su prestigioso trabajo, / descubres en el peligroso borde, que tu cuerpo es más inteligente / y que es tuyo y de todos. Todo cuerpo es tótem". Y conjura su miedo con una proclama de confianza y fe, no en los médicos (ya insuficiente), sino en la comunidad vital de todos los cuerpos, en la divinidad panteísta, en cuyo nombre sentencia: "No morirás: tus voces vegetativas siguen sonando / y ya son (y ya eres) parte del rumor panteísta que viene del bosque / y, al parecer, de un alba más remota".

La sacralización del acto médico, sobre todo del quirúrgico, por el paciente 
a través del médico -"Dios actúa por sus manos, doctor" (nunca dejamos de ser chamanes)- se realiza, según el poema, en la soledad del enfermo, mediante la entrega del cuerpo al mundo panteísta.

En los tres poemas, según el orden de esta presentación, el espacio se amplía gradualmente: "El ojo" se desarrolla exclusivamente en la interioridad del cuerpo; el yo poético se habla a sí mismo. En "Mi casa" se convoca indicios del amplio mundo social: el 'vecino' que 'estira su casa' y "Afuera soy, como todos, del trabajo y la economía" (cuerpo y ropaje social), el yo lírico monologa frente al lector. En "Como el peje-sapo", el mundo exterior-más allá de su casa- es social y también natural. Allí están: los galenos con su equipo quirúrgico (expectativa de padecimiento) y el canto de los pájaros (metáfora de vida). La voz poética, nuevamente, se habla a sí mismo (a su cuerpo) en soledad.

Este tercer poema nos introduce de lleno en el campo médico, en el mundo de la díada médico-enfermo: en el momento preoperatorio, los cuerpos uno y dos del enfermo están en relación con el cuerpo médico tres, antes que los cirujanos le abran el cuerpo. En esta instancia, en ausencia del cuerpo uno y dos del médico, en el paciente se desencadena el miedo y con este esa ausencia se torna presencia. Esta presencia configura en el lado médico, como en el caso del cuerpo del paciente, un espacio 'externo' o psicosocial, más allá del

\section{COMO EL PEJE - SAPO}

1 Nunca escuchaste canto más razonable

que el de los pájaros que anoche huían de la tormenta:

"Más vale / estar asido / del aire".

Porque en el peligroso borde palpas verso como ramita providencial

5 o frase de la filosofía como piedra para apoyar el pie,

Sí, más te hubiera valido aprender a asirte del aire.

Tendido, tu cuerpo suena sus tripas y te recuerda que

aún te quedan tus humildes voces

vegetativas. Sonríes

10 y con ternura maternal oyes tu borborigmo y tu pedo,

y te serenas:

en el peligroso borde te afirmas como el peje-sapo en la roca marina,

con el vientre.

15 Callada tu mente y su prestigioso trabajo, descubres en el peligroso borde, que tu cuerpo es más inteligente y que es tuyo y de todos. Todo cuerpo es tótem.

Levántate y muestra tu desnudez al alba que ya empieza.

A las 7 los cirujanos te abrirán el pecho con sus escalpelos.

20 No morirás: tus voces vegetativas siguen sonando

y ya son (y ya eres) parte del rumor panteísta que viene del bosque y, al parecer, de un alba más remota.

físico. El hospital (cuerpo médico tres), que envuelve al paciente y le suscita temor a los riesgos de las maniobras curativas, anuncia el encuentro decisivo en el cual el cirujano, con escalpelo y 'dos ojos', mirará y actuará en el interior del cuerpo uno del paciente.

\section{LOS ESPACIOS CORPORALES POÉTICOS Y LA RELACIÓN MÉDICO-ENFERMO}

Durante el acto quirúrgico, la relación médico-paciente es asimétrica, unilateral: el médico (sus tres cuerpos) solo cuenta con el cuerpo vegetativo de su paciente como interlocutor-informante. En la situación quirúrgica del poema, el enfermo se encuentra en un coma iatrogénico inducido por la sedación anestésica; pero, es un estado semejante a los del coma patogénico, donde se tiene que recurrir a todos los métodos indirectos para completar la información clínica y decidir.

También el diálogo es unilateral cuando una persona acude a un 'chequeo' o 'despistaje' y deja que su cuerpo dialogue con el clínico. Mientras el médico no encuentre anomalía patológica alguna, no se es 'enfermo'; solo, 'potencialmente enfermo'. Esta potencialidad hace que el caso se ubique dentro de la práctica médica bajo el rubro genérico de 'medicina preventiva'.

Cuando el consultante tiene conciencia de que su cuerpo está afectado y acude a buscar ayuda con y por 'síntomas', la relación médico-enfermo se establece en su integridad; se cumple con las dos partes claramente definidas y fundamentales de la historia clínica, que son paralelas a las categorías de 'síntomas' y 'signos': la anamnesis y el examen clínico. La primera se realiza con la conciencia del paciente (sujeto) y corresponde a un eje diacrónico, de la historia del enfermo y su padecimiento: y, la segunda, que traza el eje sincrónico, decisivo para el diagnóstico y la evolución se realiza, en el momento del encuentro, solo con su cuerpo (objeto), en una relación asimétrica, a pesar de 
contar con la colaboración del consultante, pues el médico observa, palpa y ausculta. Los 'hallazgos clínicos' obtenidos de esta manera son los catalogados como 'signos', para diferenciarlos de los relatados por el paciente, los 'síntomas'.

En "Mi casa", la presencia del vecino ampliando su casa generaliza la existencia del cuerpo tres habitado por el 'cuerpo-en-sî': la conciencia del yo corporal que va más allá de los límites dérmicos. Podemos asumir que esta es la parte mental, cultural o psicosocial del cuerpo físico. Se llega así a la dicotomía cuerpo-mente, frente a la cual, si seguimos la lógica del poema, en extremo, 'todo es cuerpo'. Pero, en niveles diferentes y con un sentido hermenéutico que abarca y disuelve la dicotomía.

En los casos de disturbio mental severo, donde el paciente no tiene conciencia de enfermedad, la relación médico-paciente también se establece unilateralmente con el enfermo: solo la conciencia de enfermedad pone en contacto la mente del enfermo con la mente del médico y torna simétrica esa relación, por lo que deja de ser unilateral. Solamente en esa integridad de relación bilateral, la psicoterapia -actividad médica eminentemente interactiva y hermenéutica- es posible de sujeto a sujeto.

Esta disquisición sobre el cuerpo metafórico en la poética de Watanabe nos ha llevado a la relación médicoenfermo y a delimitar sus variantes. $\mathrm{Si}$ seguimos lo trazado por el poeta, el encuentro entre él y su galeno es una interacción entre los 'cuerpos' de ambos. Un encuentro complementario, angustiante, cuando esté en el quirófano; en contraste con el encuentro simétrico, gozoso, con su acompañante en el interior del 'pulposo tercer piso' de su casa (su cuerpo tres).

En el desarrollo histórico del concepto filosófico 'cuerpo', encontramos las categorías 'cuerpo para mî́ 'yo existo mi cuerpo', 'el cuerpo es para otro' y 'el otro se revela a mí como sujeto para el cual soy objeto’ de Jean-Paul Sartre.
La tercera parte de El ser y la nada ${ }^{(11)}$ se titula "El Para-Otro", el que, a su vez, comprende tres capítulos: "La existencia del prójimo", "El cuerpo" y "Las relaciones concretas con el prójimo" que culmina con el 'ser-con' (Mitsein), 'nosotros'. En una simplificación escolar: tú, yo, nosotros. Las ideas sartreanas nos parecen fundamentales para comentar los conceptos evocados en los poemas de Watanabe, incluyendo el de 'relación médico-paciente' y de 'enfermedad'.

El razonamiento de Sartre anuncia el concepto moderno de 'causalidad circular', piedra angular de la teoría sistémica y de la cibernética, así como de sus aplicaciones en la teoría de la comunicación humana. Los teóricos de la pragmática de la comunicación citan a los existencialistas y a Martin Buber (el filósofo del diálogo) cuando se refieren a otro de sus axiomas, el que afirma que hay dos niveles en la comunicación: contenido y relación ${ }^{(3)}$. Lo primero se refiere al mensaje en sí que se transmite y lo segundo a la propuesta de relación entre las personas que se comunican. Podemos reunir los conceptos en una secuencia relacional: al transmitir un mensaje, yo, como sujeto, me propongo como creo que soy, delante de ti, para que me observes como objeto y para que confirmes o rechaces mi propuesta de mí mismo; finalmente, la percepción que tengo de mí mismo, como sujeto, es el resultado de la interacción entre mi propuesta inicial y la que tú me transmites al verme como objeto.

El hecho de observar nos conduce al problema del observador formulado científicamente por Heinz von Foerster ${ }^{(12)}$ como la 'cibernética de segundo orden' o 'cibernética de la cibernética', que incluye al observador dentro del campo observado. En el mundo visual de los poemas que revisamos, se incluye al lector (que interpreta el poema) convertido en observador del yo poético, cuando este se observa a sí mismo y descubre -supone o crea- al 'ojo' que observa el interior de su cuerpo.

\section{LA RELACIÓN MÉDICO-PACIENTE Y EL CONCEPTO DE ENFERMEDAD}

En la interacción médico-enfermo, al médico le corresponde ser poseedor del conocimiento de 'la enfermedad' y de 'las enfermedades' con el mayor grado de objetividad posible; y, al paciente, la conciencia objetiva y/o subjetiva de estar enfermo: solo en el proceso de este encuentro se decide la condición de 'enfermo'. Ambos participan en esta interacción calificada como 'amistosa' por Laín Entralgo ${ }^{(13)}$, que determina el acercamiento a una realidad que, en términos pragmáticos, se objetiva en el resultado terapéutico.

En su disquisición sobre el cuerpo, Sartre dice que es sujeto para sí mismo, pero objeto para el otro. Maurice Merleau-Ponty opina que ambos son 'sujetos'. Watzlawick y col ${ }^{(3)}$, los pragmáticos de la comunicación humana, postulan -en otro de sus 'axiomas'- que existen dos formas de interactuar entre los que se comunican: la complementariedad basada en la diferencia, y la simetría, en la similitud. Si aplicamos esta diferenciación práctica, Sartre propone una relación complementaria y Merleau-Ponty una simétrica entre el Ego y el Alter. En nuestra aplicación médica, observamos, como lo hemos mostrado, que en la relación médico-enfermo se dan ambas formas; aunque la medicina biologista moderna a ultranza parece que intenta rígidamente adjudicarse el rol de sujeto para sí misma y el de objeto para el paciente.

En la Introducción a la filosofía de la medicina, Wulff, Pedersen y Rosenberg ${ }^{(14)}$, al presentar el problema de la naturaleza de la enfermedad, se oponen al concepto mecanicista, puramente biológico y 'objetivo' de la enfermedad, y dan importancia al 'sentirse enfermo', a la subjetividad: "la principal preocupación de la medicina clínica es la enfermedad subjetiva y la salud subjetiva" (p. 86). Declaran su discrepancia con la medicina puramente biológica:

la medicina clínica es algo más que biología aplicada. Los clínicos han de tener también en cuenta la expe- 
riencia de dolor y sufrimiento de sus pacientes, su respeto por sí mismos, sus objetivos en la vida, etc., y han de aprender a tratar con este tipo de fenómenos no biológicos en forma racional (p. 94).

Ante la definición del concepto 'enfermedad', los mismos autores citan la monografía de Kräupt-Taylor ${ }^{(15)}$ : "trata de cortar el nudo gordiano al definirla como un estado que provoca un interés terapéutico", y proponen tres 'indicadores de morbilidad':

Existe: a) la preocupación terapéutica de una persona por sí misma; b) la preocupación terapéutica que provoca en su ambiente social, formado por personas no especialistas, y c) la preocupación terapéutica por su persona que despierta en su médico. No todo paciente tiene que presentar todos estos indicadores de morbilidad, pero sí ha de tener al menos uno de ellos.

El Diccionario de Filosofía de Ferrater Mora ${ }^{(4)}$ no incluye el concepto 'enfermedad', pues parece no haber sido atractivo para la disquisición filosófica, a pesar de que los existencialistas al tocar el tema del cuerpo abundan en ejemplos del cuerpo enfermo. Sí lo es, por el contrario, el concepto 'conciencia' y hasta el de 'tipos de conciencia' (sin incluir el de conciencia de enfermedad). Encontramos, más bien, el concepto de 'conciencia infeliz' descrito por Hegel, "el alma alienada [enajenada] que es la conciencia de sí como dividida, un ser doblado y meramente contradictorio" (p. 563), que es lo más aproximado al de "conciencia de enfermedad' que buscamos. Ferrater Mora sigue la evolución de este concepto hegeliano y llega a Grégoire, "quien señala que la Fenomenología describe el itinerario de la conciencia desdichada y de su progresivo apaciguamiento hasta el estado de satisfacción que es el 'saber absoluto". He ahí otro concepto que podría corresponder al de 'salud', tampoco recogido en el Diccionario; pero que se encuentra en la misma categoría, aunque en el otro extremo, de con- ciencia infeliz. Si volvemos a nuestro encuentro entre el galeno y su cliente, podemos superponer los conceptos 'saber absoluto' (salud) en el médico y 'conciencia infeliz' en el enfermo, ambos situados en los polos de la misma categoría.

Parafraseando a Sartre, podemos decir que no existe ni la medicina ni la enfermedad; existen los médicos y los enfermos y el encuentro entre ellos. Por eso, se distingue la medicina científica, la medicina clínica y la práctica clínica que, en otros términos, corresponden a los niveles de ciencia pura, tecnología y técnica. La concepción lineal tiende a colocar a la praxis en el extremo de una pendiente cuya cumbre es la ciencia pura. En una concepción circular, podemos apreciar lo inverso: los problemas de la aplicación técnica incitan a la ciencia pura con nuevas preguntas surgidas al integrar múltiples visiones que van más allá de la razón: "Callada tu mente y su prestigioso trabajo, / descubres en el peligroso borde, que tu cuerpo es más inteligente", advierte Watanabe.

Los tres niveles, teórico-prácticos, se reúnen en el acto médico, en la relación entre el médico y el enfermo, en el proceso cuyo hilo conductor es la dolencia, la enfermedad -real o imaginaria- que se construye y desconstruye en el devenir de ese vínculo dual. La enfermedad (o más bien el enfermo) primero 'existe' en su cuerpo (y en la mente del médico), y después 'se hace' en la interacción, en el 'ser con' (Mitsein), en el 'nosotros' de la relación médico-enfermo-

La complejidad del encuentro entre médico y enfermo, vista desde la perspectiva del médico, ha sido resumida por Laín Entralgo ${ }^{(13)}$ (1964) en cuatro 'momentos': un momento afectivo, de relación humana; un momento cognitivo, el del diagnóstico, apoyado en conocimientos científicos puros; un momento operativo, el del tratamiento, donde la individualidad del enfermo cobra presencia; y un momento éticoreligioso trascendente.
Por otro lado, diremos que la enfermedad nos pone en 'el peligroso borde' watanabeano, el cual, en palabras de Laín Entralgo ${ }^{(16)}$-ahora desde el punto de vista del enfermo- nos hace conocer el dolor físico, nos muestra la vulnerabilidad y menesterosidad de nuestra existencia, así como su valor, su cuestionabilidad e interpretabilidad. La disquisición sobre "La fenomenología del cuerpo" de Alphonse De Waelhens ${ }^{(17)}$ está llena de ejemplos de dolencias corporales, en los cuales resalta el dolor, como lo hace Sartre, de quien cita: "yo existo mi dolor". Suponemos que cuando Watanabe escribió "El ojo" no padecía dolores; no encontramos el clamor del paciente adolorido. Eso explica la necesidad de un tercer ojo explorador con la esperanza de que él informe; el dolor lo hace innecesario, se anuncia a sí mismo, el dolor existe en la conciencia.

\section{CONCLUSIONES}

La concepción del cuerpo en los poemas "El ojo", "Mi casa" y "Como el peje-sapo" de José Watanabe, desde nuestra interpretación que delimita tres espacios corporales (biológico, psicológico y socio-cultural), constituye una explicación cotejable con la de la filosofía del siglo XX (Sartre, MerleauPonty, Popper \& Eccles y otros).

La hermenéutica de este correlato poético-filosófico es una perspectiva que facilita la comprensión fenomenológica de la relación circular entre el médico y el enfermo, en cuyo proceso emerge la conceptualización de la enfermedad.

\section{COLOFÓN}

La aflicción del cuerpo, la enfermedad, incita al desarrollo de la investigación científica, de la inspiración artística y de la reflexión filosófica. Por eso, -como la angustia vista por Kierkegaard-no solo es 'normal', sino que, en la utópica búsqueda de la inmortalidad, es 'necesaria'. 


\section{REFERENCIAS BIBLIOGRÁFICAS}

1. Vattimo $\mathrm{G}(\mathrm{Ed})$. Filosofía y poesía: dos aproximaciones a la verdad. Barcelona: Gedisa.1999:12.

2. Watanabe J. Cosas del cuerpo. Lima: El caballo rojo. 1999:21,29.

3. Watzlawick P, Beavin, JH, Jackson DD. Teoría de la comunicación humana. Interacciones, patologias y paradojas. Barcelona: Herder. 1983.

4. Ferrater-Mora J. Diccionario de filosofia ( $3^{\mathrm{a}}$ ed.), 4 vol. Madrid: Alianza Editorial. 1981:690-6.

5. De-Paz M. El ombligo en el adobe. Asedios a José Watanabe. Lima: Mesa Redonda. 2010.

6. Watanabe J. El huso de la palabra. Lima: Editorial Colmillo Blanco. 1989:77.

7. Hawkins S. El universo en una cáscara de nuez. Barcelona: Planeta. 2003
8. Merleau-Ponty M. Fenomenologia de la percepción Barcelona-México: Planeta-Artemisa. 1985.

9. Popper Karl, Eccles J. El yo y su cerebro. Barcelona: Labor. 1982.

10. Bachelard G. La poética del espacio. México: Fondo de Cultura Económica. 1983:254.

11. Sartre JP. El Ser y la Nada: ensayo de ontología fenomenológica. Buenos Aires: Losada. 1966. (L'Être et le Néant. Essai d'ontologie phénoménologique. Paris: Gallimard.1943).

12. Von Foerster H. Las semillas de la cibernética. Obras escogidas. Barcelona: Gedisa. 2006.

13. Laín-Entralgo P. La relación médico-enfermo. Historia y teoría. Madrid: Revista de Occidente. 1964.

14. Wulff HR, Pedersen SA, Rosenberg R. Introducción a la filosofia de la medicina. Madrid: Triacastela. 2002.
15. Krüpt-Taylor F. The concept of illness, Disease and Morbus. Cambridge University Press. 1979:69-71. Citado en Wulff, Pedersen y Rosenberg. 2002:89.

16. Lain-Entralgo P. La experiencia de la enfermedad. En Azorin y otros: Experiencia de la vida. Madrid: Alianza Editorial. 1966:51-107.

17. De-Waelhens A. La Phénoménologie du corps. Revue Philosophique de Louvain. Troisième série 1950:48(19):371-97.

Artículo recibido el 17 de julio de 2012 y aceptado para publicación el 8 de agosto de 2012.

Correspondencia:

Correo-e: joselining@gmail.com 